\title{
The Perspectives of Kwame Nkrumah University of Science and Technology Dental School Graduates
}

\begin{abstract}
Alex Oti Acheampong1*, Felix Ampofo Anafi², Nana Tuffuor Ampem Gyimah ${ }^{3}$, Ama Amuasi', Solomon Obiri-Yeboah', Daniel Kwesi Sabbah1, Alfred Nyarko ${ }^{3}$, Merley Newman Nartey", Patrick Ampofo ${ }^{4}$, Stephen Ankoh ${ }^{1}$, Joseph Abu-Sakyi', Isaac Kwaku Asiamah ${ }^{3}$, Robert Nii Lamy

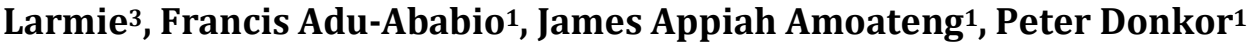

\author{
${ }^{1}$ Kwame Nkrumah University of Science and Technology Dental School, Kumasi, Ghana \\ ${ }^{2}$ Kumasi South Hospital, Kumasi, Ghana \\ ${ }^{3}$ Komfo Anokye Teaching Hospital Oral Health Directorate, Kumasi, Ghana \\ ${ }^{4}$ University of Ghana School of Medicine and Dentistry, Accra, Ghana \\ Email: *aaotiacheampong.chs@knust.edu
}

How to cite this paper: Acheampong, A.O., Anafi, F.A., Gyimah, N.T.A., Amuasi, A., Obiri-Yeboah, S., Sabbah, D.K., Nyarko, A., Nartey, M.N., Ampofo, P., Ankoh, S., Abu-Sakyi, J., Asiamah, I.K., Larmie, R.N.L., Adu-Ababio, F., Amoateng, J.A. and Donkor, P. (2018) The Perspectives of Kwame Nkrumah University of Science and Technology Dental School Graduates. Open Journal of Stomatology, 8, 158-167. https://doi.org/10.4236/ojst.2018.85015

Received: February 22, 2018

Accepted: May 7, 2018

Published: May 10, 2018

Copyright (c) 2018 by authors and Scientific Research Publishing Inc. This work is licensed under the Creative Commons Attribution International License (CC BY 4.0).

http://creativecommons.org/licenses/by/4.0/

\begin{abstract}
Background: The idea of establishing a Dental school at the Kwame Nkrumah University of Science and Technology (KNUST) was borne out of a need. There was a shortfall in the supply of dental surgeons, especially in the northern half of the country. Aim/Objective: To seek for feedback from KNUST Dental school graduates over the past six about their overall assessment of the BDS courses taught during their clinical training and challenges faced in the course of their training. Methodology: A cross-sectional retrospective study of all KNUST Dental school graduates from 2012 to 2017. A structured goggle form questionnaire was developed. The Google form link was emailed to the representatives who in turn forwarded the link to their year mates. The questionnaire was filled online and submitted as requested. Results: This represented $63.0 \%$ of the entire graduates from KNUST Dental School. The male to female ratio was 1.3:1.0. The age range of our graduate was from 24 yrs $(3.8 \%)$ to 32 years $(1.9 \%)$. The average age was 26.3 years. $48.10 \%$ of respondents said their training was very good. The major challenges were inadequate clinical space (25.2\%) and lack of materials and dental chairs for students' clinic (27.3\%). Conclusion: On the whole, the quality of the training was rated as very good even though some of the courses taught during the clinical training were rated as poor. Inadequate dental chairs, laboratory and clinic materials, supervision of student's clinic were some of the major challenges expressed by the graduates.
\end{abstract}




\section{Keywords}

Dentistry, Perspective, Graduates, Challenges, Students

\section{Introduction}

In 1974, the university of Ghana medical school now School of Medicine and Dentistry (SMD) initiated the development of a Dental school. The basic science courses were offered at the Medical school while the clinical programs were pursued at the University of Lagos (Nigeria), the University of Manchester and the University of London in the United Kingdom. In 1992, the clinical courses became fully localized. The University of Ghana therefore granted dentistry a faculty status and the first batch of locally trained dental surgeons graduated in 1997.

In an editorial commentary written by Peter Donkor [1] in 2006 in the Ghana Medical Journal, he made the following remarks "for Ghana to have an effective oral health policy, manpower planning should be comprehensive and must not be the preserve of any interest group but rather the product of collaboration between all the major stakeholders in the country".

The idea of establishing a Dental school at the Kwame Nkrumah University of Science and Technology (KNUST) was borne out of a need. There was a shortfall in the supply of dental surgeons, especially in the northern half of the country. This was because, there was only one dental school at the university of Ghana, for the training of Dental surgeons for Ghana which had a population over twenty million. Most of the graduates were located in the southern part of Ghana especially the capital city (Accra).

The first intake of undergraduate students for training in Dentistry at the College of Health Sciences (CHS) was in the 2006/7 academic year. This was made up of eleven students, seven (7) males and four (4) females. The 3-year pre-clinical course leading to a BSc in Human Biology is taken with medical students and is fully handled by the School of Medical Sciences. This is then followed by a 3-year clinical training which leads to the award of the Bachelor of Dental Surgery (BDS) degree.

Out of the first batch of eleven students, eight (8) graduated in 2012 (Figure 1).

The total number of graduates from the KNUST Dental School had since risen to 100 as of 2017. There has been an increase in the number of admissions over the last four as seen in Table 1.

Dental students are known to undergo more stressful periods especially during their clinical training [2] [3]. This is because they have to perform procedures on patients to meet their clinical requirements. A study in Nigeria [4] on perceived sources of stress in Nigerian dental students revealed that the stresses peak in the $5^{\text {th }}$ year and reduce slightly in the final $\left(6^{\text {th }}\right)$ year. The top most stressors 


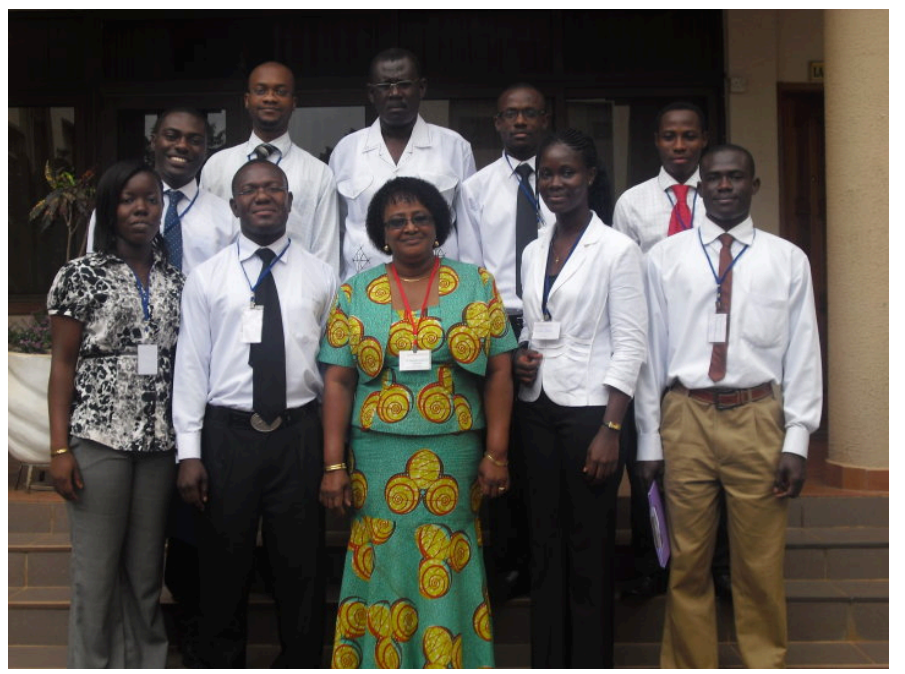

Figure 1. First batch of students together with Dr. Adu-Ababio (foundation dean) and Dr. Josephine Sackeyfio (President, Ghana Dental Association, 2009).

Table 1. Trends in student admission (2012 to 2017).

\begin{tabular}{cccc}
\hline Year & Total students population & Male & Female \\
\hline 2012 & 48 & 23 & 25 \\
2013 & 38 & 17 & 21 \\
2014 & 34 & 12 & 22 \\
2015 & 23 & 14 & 9 \\
2016 & 32 & 14 & 18 \\
2017 & 40 & 24 & 16 \\
Total & 215 & 104 & 111 \\
\hline
\end{tabular}

according to this study appeared to be the lack of financial support for dental education by government and inadequate infrastructure.

In the light of the above, some dental schools like the Cleveland Dental School have eliminated some of the requirements for students in the curriculum and have replaced it with a competency-based clinical training programme with emphasis on comprehensive patient care [5].

Dagenais et al. [6] recommended the use of a multi-method approach of both qualitative and quantitative data, and inclusion of feedback from a variety of stakeholders, including students to know about the quality of training of dental surgeons. There is growing awareness that learners' views of their educational experiences are important in shaping and modifying the educational process. The results of a recent survey [7] of dental students, regarding qualities of a good teacher were presented at the American Dental Education Association Annual Session. Based on the survey results, the authors identified several characteristics associated with effective teaching, including mastery of basic lecturing skills, clear organization, effective demonstrations, and punctuality/ availability.

The current students' population in KNUST Dental school is 215 (Table 2) 
including 20 foreigners. The school has not seen much expansion in terms of the faculty and physical infrastructure.

The primary aim of this study was to solicit feedback from KNUST Dental school graduates over the past six years since its first products graduated about their overall assessment of the BDS courses taught during their clinical training and challenges faced in the cause of their training. The secondary aim was to look at the job market for our graduates and the type of progress they have made by way of career development.

\section{Materials and Method}

This was a cross-sectional retrospective study of all KNUST Dental school graduates from 2012 to 2017. The estimated respondents were 100 representing the total number of graduates over the study period. A structured electronic questionnaire was developed and the following information sought from respondents: demographics, employment, academic progression, perception of quality dental training, challenges during clinical training, and suggestions for improvement.

Respondents were assured of confidentiality of their personal identity and the information they provide to encourage them to be more objective with their answers. The various year groups' class representatives were identified and contacted. The Google form link was emailed to the representatives who in turn forwarded the link to their year mates. The questionnaire was filled online and submitted as requested. There were some open ended questions which required non-structured responses. These responses were summarized and analyzed. Descriptive Statistical analyses were used for the quantitative data. Graphs were used to represent continuous variables and Pie chart for categorical variables.

\section{Results}

Out of the 100, 63 responded, representing a $63.0 \%$ rate of response. The male to female ratio was 1.3:1.0. The age range of the graduate was $24-32$ years with an average age of 26.3 years. There was an increase in the number of graduates over the last three years as seen in Table 2.

Majority of the graduates are employed by the Ghana Health Service (40.7\%)

Table 2. Showing graduates from KNUST dental school.

\begin{tabular}{cccc}
\hline Year & Graduates & Male & Female \\
\hline 2012 & 8 & 6 & 2 \\
2013 & 13 & 6 & 7 \\
2014 & 5 & 2 & 3 \\
2015 & 17 & 15 & 2 \\
2016 & 22 & 13 & 9 \\
2017 & 35 & 24 & 11 \\
\hline
\end{tabular}


followed by Teaching Hospitals (33.3\%). Only 16.7\% worked in into private practice as seen in Figure 2.

Nine $(14.2 \%)$ out of the 63 respondents were undergoing postgraduate training, with the majority (90.0\%) being in the residency training programme of the Ghana College of Physicians and Surgeons and 2.0\% had earned Master Public Health degrees. The rating of the general performance of clinical courses taught is as shown in Figure 3.

The rating for the individual courses was as shown below.

\section{Discussion}

Kwame Nkrumah University of Science and Technology Dental School is the second dental school in Ghana. The School has so far trained 100 dentists serving in various parts of Ghana. From the above study the average age of our graduates at the time of this study was 26.3 years. This means that our graduates are likely to contribute to the public work force of Ghana for over three decades

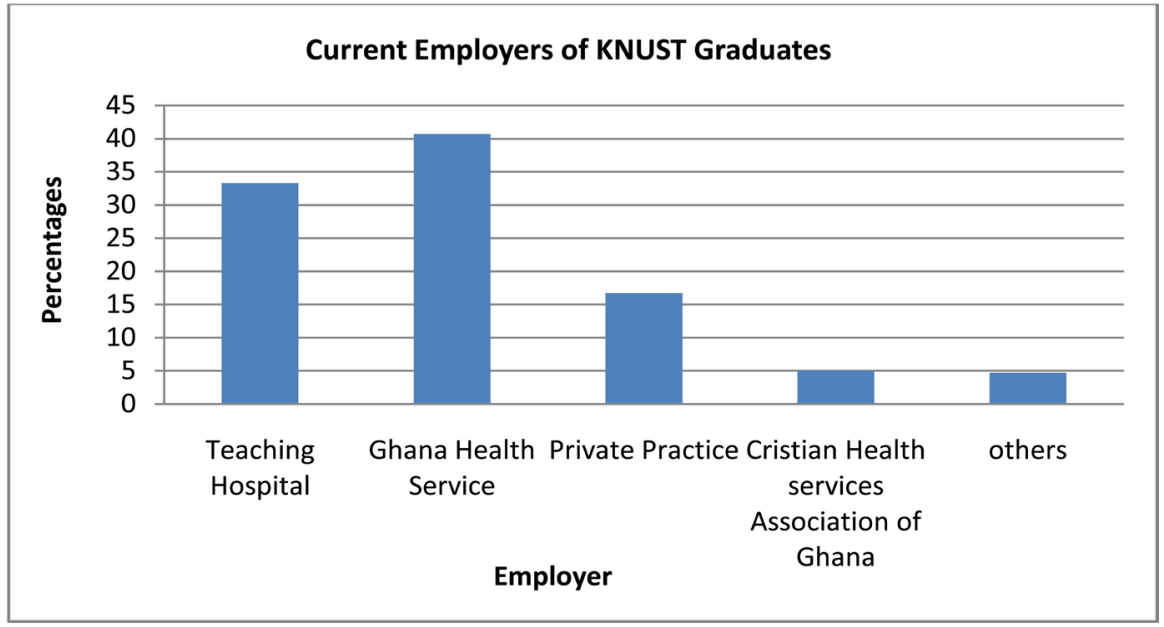

Figure 2. Showing current employers of KNUST dental school graduates.

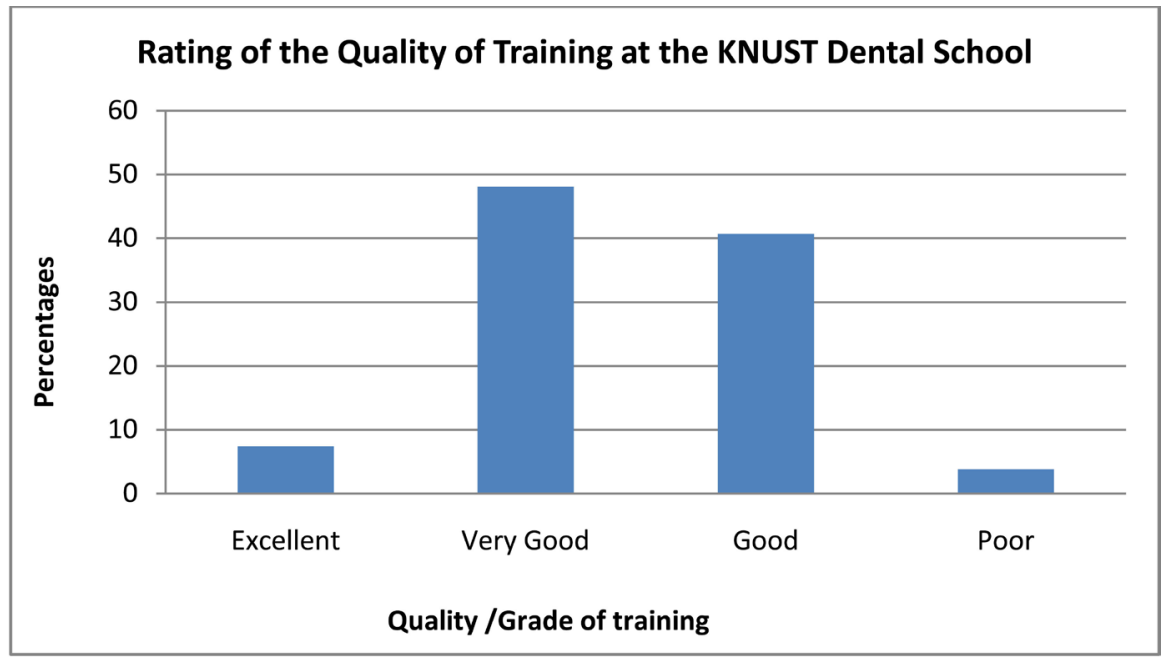

Figure 3. Showing perceived quality of training at KNUST Dental School. 
before retirement with the possibility that some of them may opt for faculty positions. For that reason their views are very important in improving on the quality of training of dental surgeons from KNUST.

Majority of our graduates pursued their Housemanship training in Komfo Anokye Teaching Hospital and 37 military hospitals in Accra. The major employers of our graduates are the Ghana Health Services and the Teaching hospitals even though a few are into private practice. The KNUST Dental can introduce entrepreneurship courses in their curriculum to help their graduates venture into private practice to reduce the current difficulty associated with public sector employment from the central government.

In general majority of the graduates thought their training was very good even though a limited number were not happy with the quality of their training. The study did not probe further to know why some of the graduates were not happy. Further studies should be able to address this and will help in improving upon for the curriculum.

The graduates rated Oral Radiology lowest and OMFS highest in terms of the quality of teaching as indicated in Figure 4 and Figure 5. It is assumed that this reflects the availability or otherwise of adequate faculty for the various courses. In the specialties that had adequate numbers of faculty and residents that also assisted with teaching, rating of teaching was much higher. The lack of adequate faculty impacted negatively on the quality of teaching and needs to be addressed as a matter of urgency.

This study also enquired about graduates' challenges during the training as shown in Table 3. The lack of adequate dental chairs and materials were the

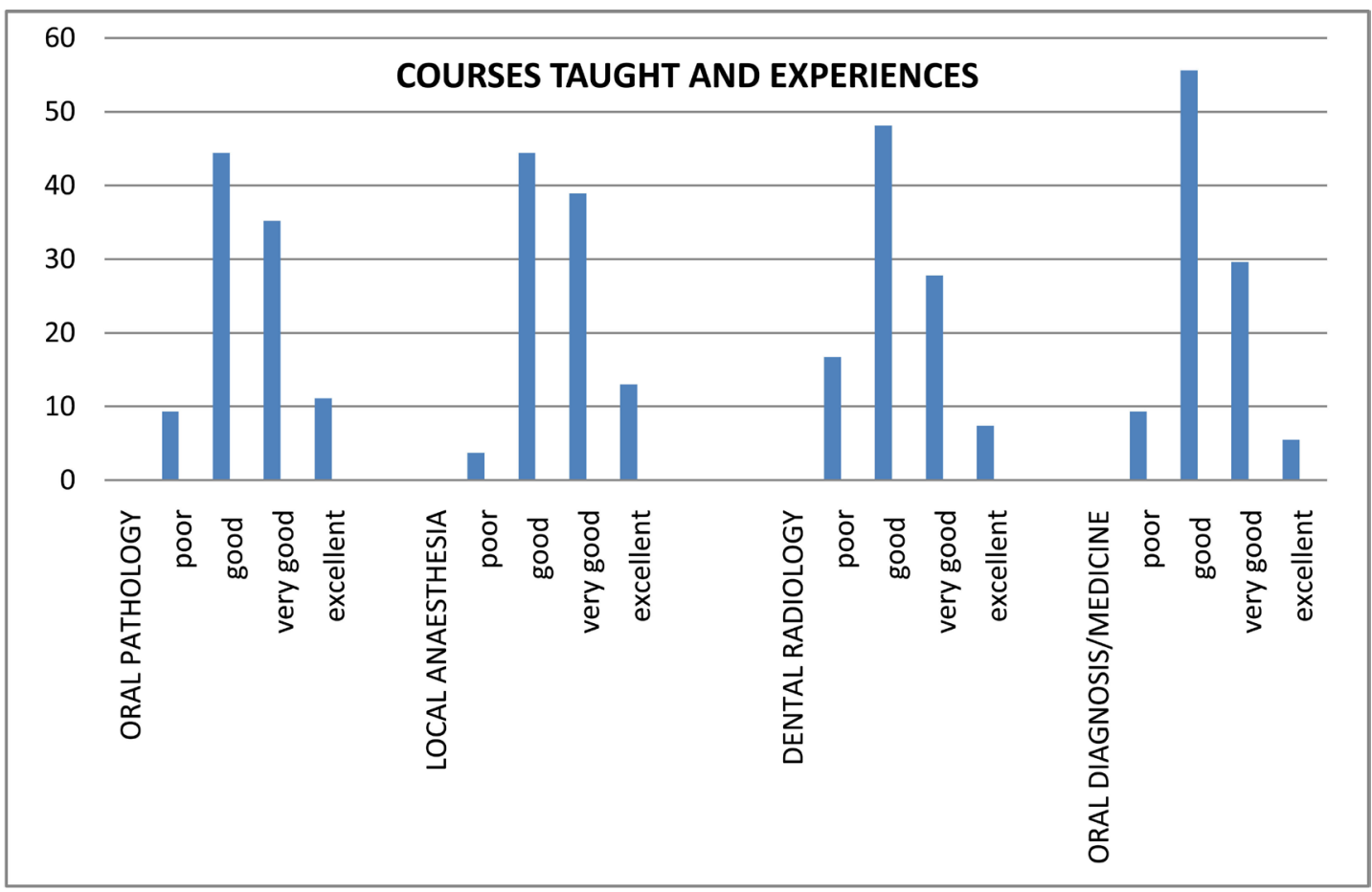

Figure 4. Showing rating for oral pathology, local anaesthesia, dental radiology and oral medicine. 


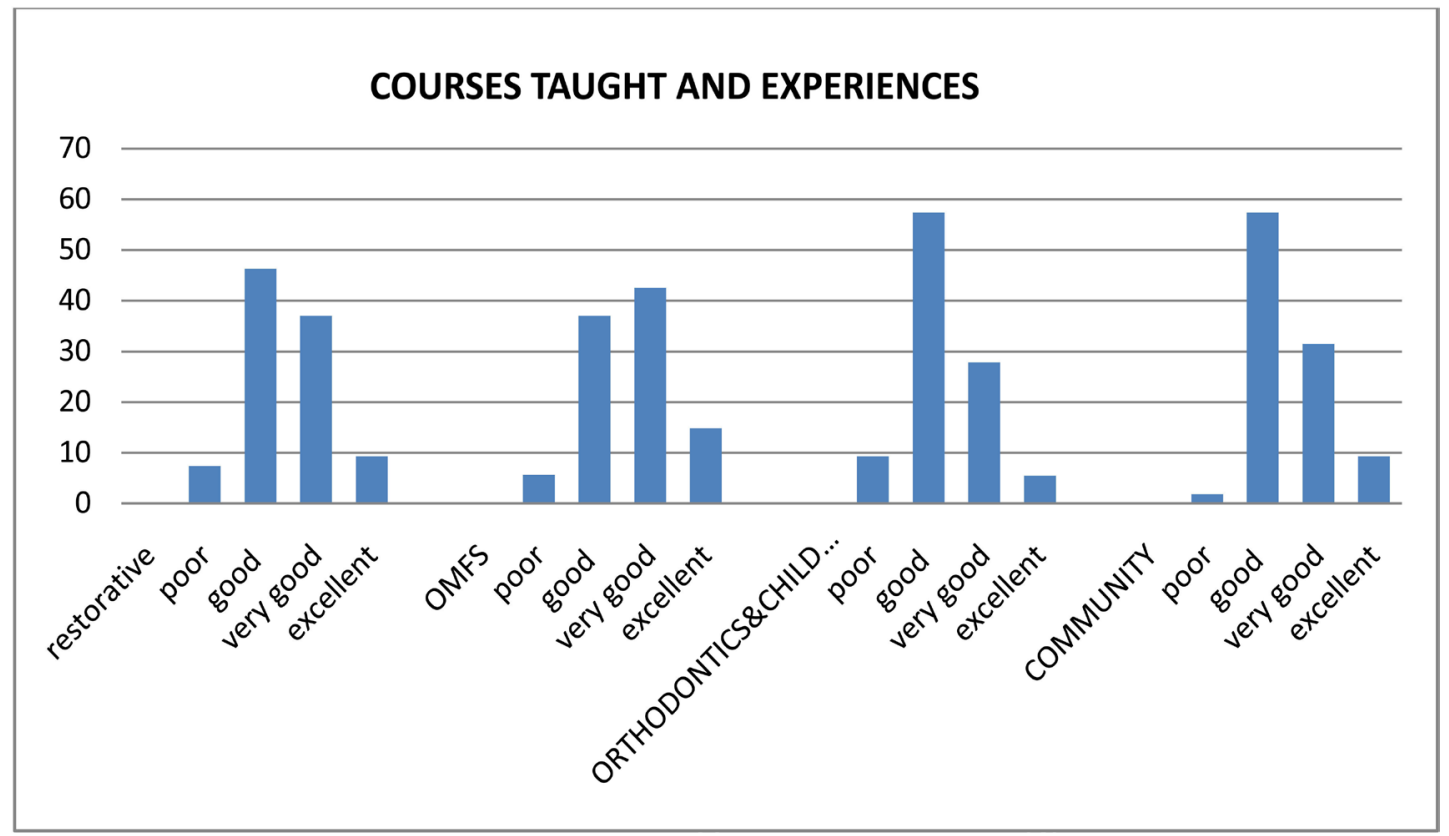

Figure 5. Showing ratings in restorative, oral and maxillofacial, orthodontics and community dentistry.

Table 3. Showing challenges expressed by graduates.

\begin{tabular}{ccc}
\hline & Challenges during training & Percentage of response \\
\hline 1 & Inadequate clinical space & 25.2 \\
2 & Inadequate dental chairs and materials & 27.3 \\
3 & Lack of clinical supervision & 15.0 \\
4 & Unfriendly examination time table & 1.50 \\
5 & Low patients attendance at student's clinic & 17.0 \\
6 & High cost of students' clinic charges & 4.0 \\
7 & Inadequate lecturers and supporting staff & 2.5 \\
8 & High course load & 1.0 \\
9 & Unfriendly block lectures & 3.0 \\
10 & Unhealthy lecturer students relationship & 1.6 \\
11 & Stress & 1.9 \\
\hline
\end{tabular}

most highly ranked challenges followed closely by inadequate clinical space. Graduates were also of the view that, there was inadequate supervision of student's clinical work and laboratory training. The above views expressed are very important since dental training is practical oriented. Therefore, lack of supervision and dental chairs can go long way to affect the overall quality of future dental surgeons from KNUST Dental School.

In a study [8] that looked at effective ways of teaching and learning in dental schools, the following characteristics of effective learning experiences were identified: 1) instructor characteristics (personal qualities, "checking-in" with students, and an interactive style); 2) characteristics of the learning process (focus 
on the "big picture," modeling and demonstrations, opportunities to apply new knowledge, high-quality feedback, focus, specificity and relevance, and peer interactions); and 3) learning environment (culture of the learning environment, technology). The adoption of the above approach should be the way forward in KNUST Dental School to enhance adequate supervision and clinical skills acquisition for students. A growing number of dental schools [7] are moving toward increasing the amount of time their students spend in active learning situations, while decreasing the amount of time spent in the traditional lecture rooms. This study suggests that student's desire guidance, in the form of modeling, demonstrations, and positive interactions with instructors.

Another worrying phenomenon was the lack of patients for the students' clinic. This could be the fact that patients attending students' clinic are made to pay the same amount as when seen by a specialist in the KATH Oral health Directorate. This practice is very unusual since most dental schools have subsidized fees for procedures done by students under supervision. This is usually the means used to motivate patients to attend students' clinic so they can meet their clinical requirements and competency.

Inadequate faculty and supporting staff was also a major challenge. Thus the school relied on external faculty for teaching in Oral Pathology and Paediatric Dentistry who gave block lectures requiring students to stay in lectures rooms for extended periods of time. This proved stressful for some of the students. This lack of faculty could be addressed if as a matter of urgency some of the promising graduates are supported to undergo further training in the various specialties.

Poor lecturer-students communication was perceived added to the stress on students during their clinical training. Stress among our students should be a major concern to all of us. Dental schools have long been known to have extremely demanding and nerve-racking learning environs [2]. This may be attributed to modern-day curricula requiring dental students to accomplish various proficiencies in addition to acquiring sound theoretical knowledge, clinical skills and at the same time maintaining a high degree of professionalism. As such, psychological stress amongst dental students has been evaluated by many researchers across the globe [9]. Psychological stress ensues when perceived environmental demands on a dental student outweigh his or her capacity to adapt. These stresses increase the risk of disease and result in psychological and biological tissue changes [10]. According to Polychronopoulou et al. [11], dental students undergo more anxiety than the general populace leading them to higher degrees of depression, obsessive-compulsive disorders, alcohol abuse and mortality. This phenomenon manifested among this cohort of students who sometimes broke down and required referral to a clinical psychologist for assistance. It may be necessary to review the current clinical requirements by students to a more competency evaluation as in some institutions. There must also be expansion of the current infrastructure and human resources to match the increases in student enrolment as also suggested by the graduates in Table 4 . 
Table 4. Suggestions for improving training.

\begin{tabular}{ccc}
\hline & Suggestion & Percentage of response \\
\hline 1 & Expansion of students' clinical space & 43.0 \\
2 & Increase number of faculty & 24.5 \\
3 & Encourage past graduates to join faculty & 10.4 \\
4 & Effective clinical and laboratory supervision & 12.1 \\
5 & Patients attending students clinic should pay subsided fees & 10.0 \\
\hline
\end{tabular}

\section{Conclusion}

This study sought feedback from the KNUST Dental School graduates over the past six year years. On the whole, the quality of the training was rated as very good even though some of the clinical courses were considered to be poorly taught. Inadequate dental chairs, laboratory and clinic materials, supervision of students were some of the major challenges expressed by the graduates. This recent increase in student intake is a wakeup call for the KNUST Dental School to expedite action on both infrastructural and human resource development to support effective training of dental surgeons from the University.

\section{Acknowledgements}

We are grateful to all support staff of KNUST Dental School; Mr. Matthew Amoako Mathew, Regina Nuako, Maxwell Agyemang-Yeboah, Felicia Frimpong and Mr. Samuel Larbi. We also want to appreciate the following national service personnel; Mr. Andrews Obeng, Kwasi Boateng, Michael Boakye and Jacqueline Akwaboah.

\section{References}

[1] Donkor, P. (2006) Oral Health Manpower: What Are Ghana's Requirements? Ghana Medical Journal, 40, 116-117.

[2] Sanders, A.E. and Lushington, K. (2002) Effect of Perceived Stress on Student Performance in Dental School. Journal of Dental Education, 66, 75-81.

[3] Hayes, A., Hoover, J.N., Karunanayake, C.P. and Uswak, G.S. (2017) Perceived Causes of Stress among a Group of Western Canadian Dental Students. BMC Research Notes, 10, 714. https://doi.org/10.1186/s13104-017-2979-9

[4] Sofola, O.O. and Jeboda, S.O. (2006) Perceived Sources of Stress in Nigerian Dental Students. European Journal of Dental Education, 10, 20-23. https://doi.org/10.1111/j.1600-0579.2006.00391.x

[5] Lalumandier, J.A., Victoroff, K.Z. and Thuernagle, O. (2004) Early Clinical Experience for First-Year Dental Students. Journal of Dental Education, 68, 1090-1095.

[6] Dagenais, M.E., Hawley, D. and Lund, J.P. (2003) Assessing the Effectiveness of a New Curriculum: Part I. Journal of Dental Education, 67, 47-54.

[7] Shih, W., Talwar, D., Ryn, K.E. and Hsiao, G. (2004) Qualities of a Good Teacher: The Dental Student Perspective. Journal of Dental Education, No. 2, 208.

[8] Victoroff, K.Z. and Hogan, S. (2006) Students' Perceptions of Effective Learning 
Experiences in Dental School: A Qualitative Study Using a Critical Incident Technique. Journal of Dental Education, 70, 124-132.

[9] Naidu, R.S., Adams, J.S., Simeon, D. and Persad, S. (2002) Sources of Stress and Psychological Disturbance among Dental Students in the West Indies. Journal of Dental Education, 9, 1021-1030.

[10] Abu-Ghazaleh, S.B., Sonbol, H.N. and Rajab, L.D. (2016) A Longitudinal Study of Psychological Stress among Undergraduate Dental Students at the University of Jordan. BMC Medical Education, 16, 90. https://doi.org/10.1186/s12909-016-0612-6

[11] Polychronopoulou, A. and Divaris, K. (2005) Perceived Sources of Stress among Greek Dental Students. Journal of Dental Education, 69, 687-692. 